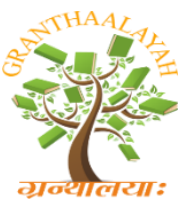

INTERNATIONAL JOURNAL OF RESEARCH GRANTHAALAYAH A knowledge Repository

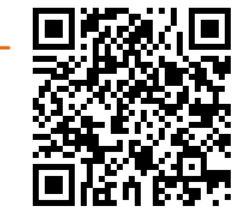

Science

\title{
SPATIAL DISTRIBUTION OF LYMPHATIC FILARIASIS IN CROSS RIVER STATE, NIGERIA: A GEOGRAPHICAL INFORMATION SYSTEMS (GIS) STUDY
}

\author{
Ukpong, Iniodu George ${ }^{* 1}$, John, Davison Mbere-obong ${ }^{2}$ \\ ${ }^{* 1,2}$ Department of Biological Sciences, Cross River University of Technology, Calabar, Nigeria
}

DOI: https://doi.org/10.29121/granthaalayah.v4.i12.2016.2398

\begin{abstract}
Effective control efforts on Lymphatic filariasis (LF) are hindered by paucity of reliable data on spatial distribution of the disease. Aim: This study was aimed at mapping and describing the transmission pattern of lymphatic filariasis in order to identify high risk zones of infection in Cross River State (CRS), to guide intervention programmes. Method: An 8-year case record (2006-2013) of Lymphatic filariasis in the 18 local government areas (LGAs) of CRS was mapped using geographical information system, (GIS); employing the graduated colour map with natural break classification method. Thematic (LF incidence) maps generated in ArcView 3.1 were overlaid on vegetation and natural drainage maps of the state. Data on seasonal incidence were mapped through aggregation of attribute data (LF cases) by months. Data analysis was through thematic mapping and descriptive statistics. Results: Thematic maps displayed spatial variation in the distribution of LF in the state; showing Ogoja LGA with highest incidence $(61.25 \%)$ of the 800 reported cases; Ikom, the lowest; $1(0.125 \%)$ and zero case in 7 LGAs. There were no visually remarkable patterns to suggest strong influence of vegetation and natural drainage on transmission. Greater proportion $(82.12 \%)$ of cases was recorded in the dry season. Conclusion: The study has produced prevalence map of LF in the state, which could guide intervention programmes; and has also revealed paucity of data at the disposal of healthcare authorities, a situation that could hinder large scale intervention. Findings identify poor health-seeking behavior of the population and poor disease surveillance strategies in the state. Community health education, strengthening of public health apparatus and interventions through mass drug administration and integrated vector control, are recommended.
\end{abstract}

Keywords: Lympatic Filariasis; GIS; Spatial Distribution; Incidence; Wuchereria Bancrofti; Cross River State.

Cite This Article: Ukpong, Iniodu George, and John, Davison Mbere-obong. (2016). "SPATIAL DISTRIBUTION OF LYMPHATIC FILARIASIS IN CROSS RIVER STATE, NIGERIA: A GEOGRAPHICAL INFORMATION SYSTEMS (GIS) STUDY." International Journal of Research - Granthaalayah, 4(12), 101-109. 10.29121/granthaalayah.v4.i12.2016.2398. 


\section{Introduction}

Filariasis is a group of debilitating infections with threadlike parasitic nematodes of the superfamily Filaroidea, generally called filarial worms; transmitted by arthropods from the families Culicidea (mosquitoes), Simuliidae (black flies), Ceratopogonidae (biting midges) and Tabanidae (deer flies). [1]. A great many filarial worms have been described, but only eight species infect humans naturally [2]. Human filariasis is classified into three groups based on the niche of the adult worm, namely Lymphatic filariasis caused by Wuchereria Bancrofti, Brugia malayi, and Brugia timori; which occupy the lymphatic system including the lymph nodes; Subcutaneous filariasis, caused by Loa loa (the eye worm), Mansonella streptocerca and Onchocerca volvulus, which occupy the subcutaneous tissues; and Serous cavity filariasis caused by Masonella perstans and Mansonella ozzardi, which occupy the cavity of the abdomen. Of these, lymphatic filariasis and loa loa are raising very high global concern towards elimination. Loiasis, also known as Calabar swellings or African eye worm infection is endemic in 11 countries in western and central Africa, with 12 million people infected. [3][4].

However, reference to filariasis has been traditionally made to lymphatic filariasis (LF), one of the most debilitating neglected tropical diseases in the world. [5]. A leading cause of permanent or long-term disability next to leprosy, LF causes damage to the lymphatic vessels and induce such disabling effects as hydrocele, lymphedema and elephantiasis. [6][7]. Global estimates show that the disease is endemic in 73 countries, affecting 120 million people. [8]. The disease has induced huge economic losses due to ebbed productivity of victims to the tune of hundreds of millions of Dollars, intense morbidity due to chronic disfigurements as well as social stigma on patients. [6].

There have been extensive studies on the incidence of filariasis in Nigeria; [9-17]. Geographic information systems (GIS) studies have shown widespread endemicity across Nigeria, which tops the list of the 34 endemic African countries, with 80-120 million people at risk; [18-20][8]. Mapping the distribution of lymphatic filariasis has been an approach in focus in the fight against the scourge in all 73 endemic countries since the past decade. Mapping has revealed the global population living in countries requiring preventive treatment. [6]. The tool of GIS helps to determine spatial distribution and transmission patterns to aid disease control. Bearing in mind the various factors that influence transmission of vector-borne diseases, including environmental and geographical indices, and the need to generate useful data on the disease distribution, this study was aimed at mapping and describing the transmission pattern of lymphatic filariasis in order to identify high risk zones of the infection in Cross River State, a Nigerian tourist state which lies in the rain forest area of West Africa.

\section{Methodology}

\section{Study Area}

One of Nigeria's coastal states, Cross River State lies in the south eastern part of the country; straddling Latitude $4^{\circ} 28^{1}$ and $6^{\circ} 55^{1}$ north of the Equator and Longitude $7^{\circ} 50^{1}$ and $9^{\circ} 28^{1}$ east of the Greenwich Meridian. It has a land mass of 23,074 square kilometers; bordered on the East by the Republic of Cameroun and shares boundaries with the Nigerian states of Benue on the North, 
Ebonyi and Abia on the west and Akwa Ibom on the south west; and bordered by the Atlantic Ocean on the south. Owing to its location, the state enjoys a tropical climate at an altitude of 1,395.79 metres above sea level. The state also has vegetation zones such as mangrove, rainforest, guinea savanna and montane. It prides its massive wealth of one of the most treasured, biodiversity-rich tropical rainforests in the world. The area experiences two alternating seasons; wet (May-October) and dry (November-April), with an average temperature of $29^{\circ} \mathrm{C}$. The State comprises 18 Local Government Areas (LGAs) that form the major political administrative units, with a population of $2,888,966$, based on the 2006 population census. Cross River State is a leading tourism destination in Nigeria.

\section{Data Collection}

Data of reported Lymphatic Filariasis cases from the 18 local government areas (LGAs) of the state for eight years, 2006 to 2013, were obtained from the Cross River State Ministry of Health, and World Health Organization residence office in Calabar. The population structure of Cross River State in each LGA based on the 2006 Census was obtained the National Population Commission and projected to 2013. Data were grouped based on LGAs due to lack of ideal personal information. The aggregated data therefore required an area-base analysis producing other types of spatial analysis possible with point data. The database however did not contain data of privately treated filariasis cases and cases that could not be reported due to lack of accessibility to facilities, poor transport networks, low socio economic status and beliefs.

\section{Database}

The database comprised spatial map data including administrative boundaries, roads, rivers; and a relational database of relevant Lymphatic filariasis (LF) data, which included LF cases and location. The relational database consisted of two data sets, namely, the core database, made up of names and unique identification of local government areas (LGAs), in ArcView; and the Attribute data consisting of reported LF cases, in MS Excel. The latter were linked to the core data. Thus aggregation of data based on time (months) and season could be displayed and analyzed at the LGA spatial level. [21].

\section{Data Analysis}

Data analysis involved the creation of thematic maps through the GIS in order to provide a visual portrayal of the spatial distribution of filariasis in the State. Thematic mapping was used to display the spatial variation according to local government area, and to present a visual display of seasonal variation in filariasis incidence. Thematic maps were created in Arc view GIS version 3.1 (ESRI). Mapping was based on the incidence rate of Lymphatic filariasis of the 8year period (2006-2013). The mapping technique used was the graduated colour map, with natural break classification method. This enabled the modeling of spatial patterns of LF incidence, and classified observed LF incidence under four case levels of very low, low, high and very high, with natural break ranges for each case level. [22]. Seasonal incidences were also mapped following aggregation of the core database (LGAs) and attribute data (LF cases) according to months. 


\section{Results and Discussion}

\section{Results}

\section{Lymphatic filariasis Profile}

Within the 8-year study period, a total of 800 cases of lymphatic filariasis were reported in the state; with incidence rate of 5.57 cases per 10000 population. Results show that Ogoja had the highest number of reported cases; 490 (61.25\%); Ikom, the lowest; 1(0.125\%) and zero case in Akpabuyo, Biase, Boki, Calabar municipal, Calabar south, Obudu and Yakurr.

Thematic map shows the average incidence per 10000 in each LGA (Figure 1.). Of the 18 local government areas in the state, only one (Ogoja) had average incidence between 1.251 - 3.140; one (Obubra) had average incidence from 0.681 -1.250, while two (Akamkpa and Obanliku had average incidence between $0.101-0.680$ per 10000 population.

The highest yearly incidence of LF was recorded in 2012 with 617 cases $(77.12 \%)$ in a total population of 3,564,047. The lowest number of cases were seen in 2007; 30 (3.75\%) from amongst a population of 3,065,655. There were no case reports in 2009 and 2013 (Table 1).

\section{Vegetation and Spatial Distribution of Lymphatic Filariasis}

Incidence map overlaid on the vegetation map of the state produced a visual effect of vegetation on transmission of LF (Figure 2). The highest case records were in the guinea savanna vegetation zone (Ogoja LGA), average incidence /10000: 1.251 - 3.140, followed by rainforest (0.6811.250). Least incidence rates 0 - 0.100 / 10000 were found in LGAs within all vegetation zones; while zero case was recorded in LGAs in the Mangrove and Freshwater Swamp forest zone.

\section{Natural Drainage and Spatial Distribution of Lymphatic Filariasis}

The thematic map of incidence overlaid on map of rivers in Cross River State shows that both extensively drained and less drained areas had case records of LF (Figure 3).

\section{Seasonal Incidence}

The greater proportion of LF cases; $657(82.12 \%)$ were recorded in the dry season between the months of November to April; while 143 (17.86\%) were recorded between May and October, marking the wet season. The highest record was in November $(61.75 \%)$, while the lowest was in October $(0.12 \%)$. Zero case was recorded in January and December.

Table 1: Average incidence of Lympatic filariasis in Cross River State; 2006 - 2013

\begin{tabular}{|c|c|c|c|c|c|c|c|c|c|c|c|c|c|}
\hline \multirow{2}{*}{ L.G.A } & \multicolumn{8}{|c|}{ Year } & \multirow{2}{*}{$\begin{array}{l}\text { Tota } \\
\text { I }\end{array}$} & \multirow[b]{2}{*}{$\begin{array}{l}\text { Cumulative } \\
\text { Population } \\
\text { 2006-2013 }\end{array}$} & \multirow[b]{2}{*}{$\begin{array}{c}\% \\
\text { Inciden } \\
\text { ce }\end{array}$} & \multirow[b]{2}{*}{$\begin{array}{c}\text { Population } \\
\text { Average }\end{array}$} & \multirow[b]{2}{*}{$\begin{array}{l}\text { Inciden } \\
\text { ce Rate } \\
10000\end{array}$} \\
\hline & $\begin{array}{l}2 \\
0 \\
0 \\
6\end{array}$ & $\begin{array}{l}2 \\
0 \\
0 \\
7\end{array}$ & $\begin{array}{l}\mathbf{2} \\
0 \\
0 \\
8\end{array}$ & $\begin{array}{l}2 \\
0 \\
0 \\
9\end{array}$ & $\begin{array}{l}2 \\
0 \\
1 \\
0\end{array}$ & $\begin{array}{l}2 \\
0 \\
1 \\
1\end{array}$ & $\begin{array}{l}2 \\
0 \\
1 \\
2\end{array}$ & $\begin{array}{l}\mathbf{2} \\
\mathbf{0} \\
\mathbf{1} \\
\mathbf{3}\end{array}$ & & & & & \\
\hline ABI & 0 & 0 & 0 & 0 & 0 & 4 & 1 & 0 & 5 & 1313591 & 0.625 & 164198.875 & 0.03 \\
\hline AKAMPA & 2 & 0 & 0 & 0 & 0 & 40 & 0 & 0 & 42 & 1370952 & 5.25 & 171369 & 0.030 \\
\hline AKPABUYO & 0 & 0 & 0 & 0 & 0 & 0 & 0 & 0 & 0 & 2462001 & 0 & 307750.125 & 0 \\
\hline BAKASSI & 0 & 0 & 3 & 0 & 0 & 0 & 0 & 0 & 3 & 293782 & 0.375 & 36722.75 & 0.10 \\
\hline BEKWARA & 0 & 0 & 0 & 0 & 0 & 10 & 0 & 0 & 10 & 959975 & 1.25 & 119996.875 & 0.10 \\
\hline BIASE & 0 & 0 & 0 & 0 & 0 & 0 & 0 & 0 & 0 & 1534767 & 0 & 191845.87 & 0 \\
\hline
\end{tabular}




\begin{tabular}{|l|c|c|c|c|c|c|c|c|c|c|c|c|c|}
\hline BOKI & 0 & 0 & 0 & 0 & 0 & 0 & 0 & 0 & 0 & 1688604 & 0 & 211075.5 & 0 \\
\hline $\begin{array}{l}\text { CALABAR } \\
\text { MUNICIPALIT } \\
\text { Y }\end{array}$ & 0 & 0 & 0 & 0 & 0 & 0 & 0 & 0 & 0 & 1627379 & 0 & 203422.375 & 0 \\
\hline $\begin{array}{l}\text { CALABAR } \\
\text { SOUTH }\end{array}$ & 0 & 0 & 0 & 0 & 0 & 0 & 0 & 0 & 0 & 1738397 & 0 & 217299.625 & 0 \\
\hline ETUNG & 0 & 0 & 0 & 0 & 0 & 0 & 0 & 0 & 0 & 727508 & 0 & 90988.5 & 0 \\
\hline IKOM & 1 & 0 & 0 & 0 & 0 & 0 & 0 & 0 & 1 & 1958964 & 0.125 & 244870.5 & 0.005 \\
\hline OBANILIKU & 25 & 31 & 2 & 0 & 10 & 0 & 0 & 0 & 68 & 990819 & 8.5 & 123852.375 & 0.68 \\
\hline OBUBRA & 0 & 0 & 5 & 0 & 41 & 0 & 126 & 0 & 172 & 1366063 & 21.5 & 170757.875 & 1.25 \\
\hline OBUBU & 0 & 0 & 0 & 0 & 0 & 0 & 0 & 0 & 0 & 1452419 & 0 & 181552.375 & 0 \\
\hline ODUKPANI & 0 & 0 & 0 & 0 & 2 & 0 & 0 & 0 & 2 & 1819575 & 0.25 & 227446.875 & 0.01 \\
\hline OGOJA & 0 & 0 & 0 & 0 & 0 & 0 & 490 & 0 & 490 & 1559425 & 61.25 & 194928.125 & 3.14 \\
\hline YAKURR & 0 & 0 & 0 & 0 & 0 & 0 & 0 & 0 & 0 & 1746387 & 0 & 218298.375 & 0 \\
\hline YALA & 0 & 0 & 0 & 0 & 7 & 0 & 0 & 0 & 7 & 1912692 & 0.875 & 239086.5 & 0.03 \\
\hline TOTAL & 28 & 31 & 10 & 0 & 60 & 54 & 617 & 0 & 800 & 26523300 & 100 & 3207415.49 & 5.565 \\
\hline
\end{tabular}

Source: Cross River State Ministry of Health / WHO Residence office, Calabar.

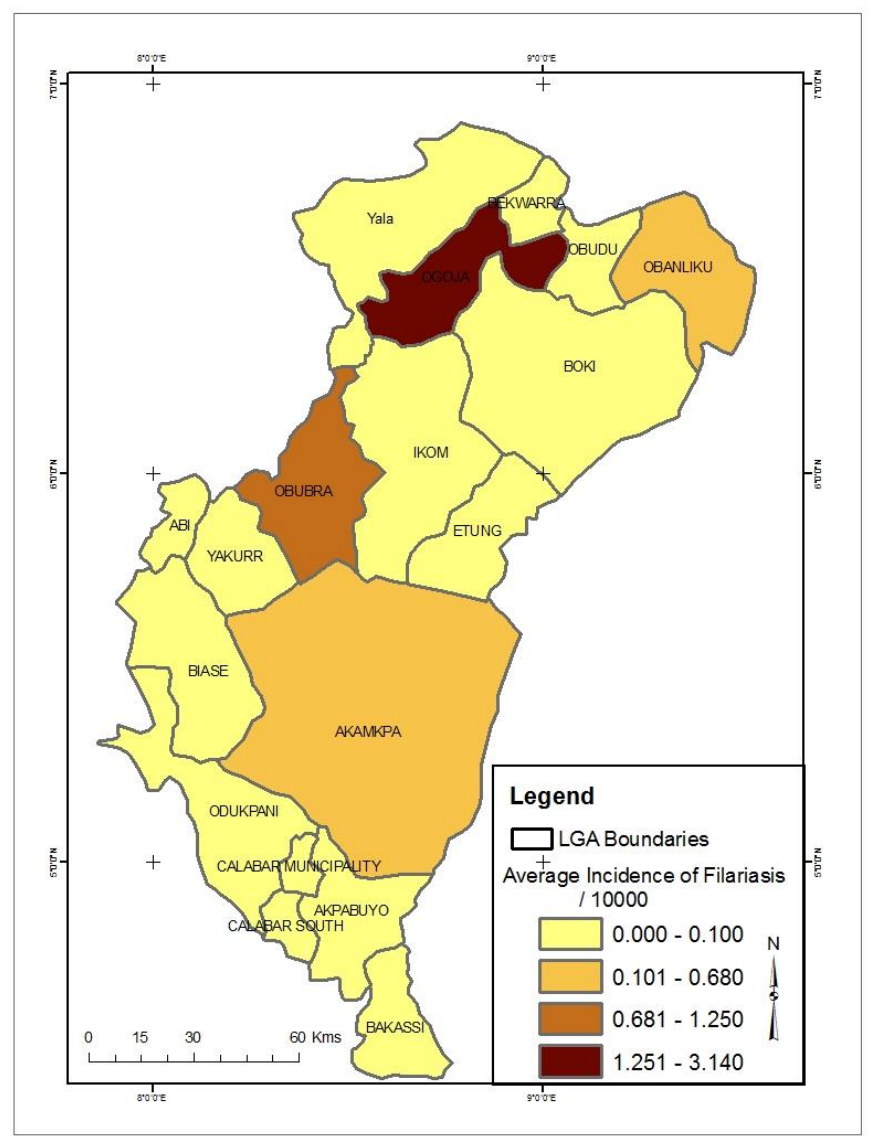

Figure 1: Map of Cross River State showing Profile of Lymphatic Filariasis 2006 - 2013 


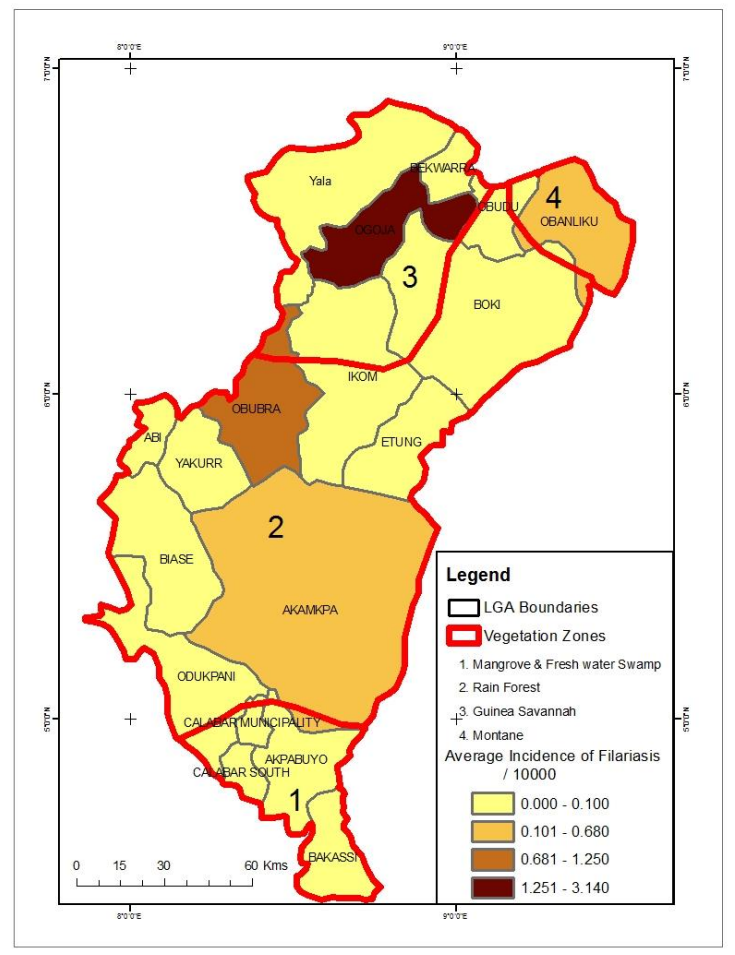

Figure 2: Lymphatic Filariasis incidence and Vegetation

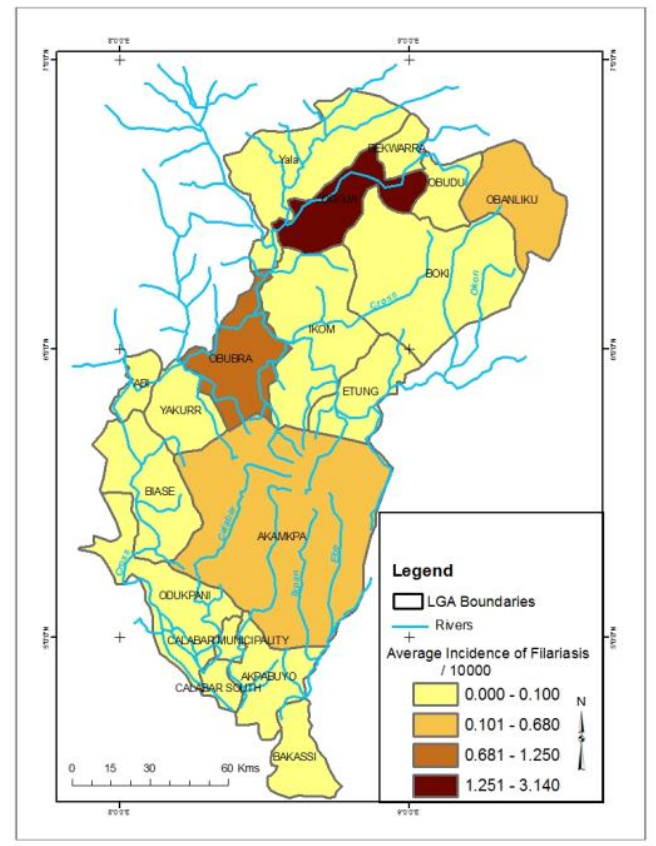

Figure 3: Lymphatic Filariasis Incidence and Natural Drainage 


\section{Discussions}

Although widespread endemicity of Lymphatic filariasis in Nigeria has been documented (WHO 2010, Okorie et al., 2013), and have been extensively reported in Cross River State, there remains the need to identify high prevalence areas as very high risk zones to facilitate control and elimination efforts. Application of geographic information systems (GIS) techniques in this study has enabled the mapping of such high risk zones; as well as revealed the gap in healthseeking and healthcare delivery mechanisms in the state. It has produced a visual image of the data, which shows that LF transmission might not be clustered in a particular area of the state, although there are seeming differences in prevalence across geographical boundaries. The finding in this study corroborates previous studies which reported $15.5 \%$ case positive and $6.8 \%$ overall prevalence of LF in Obubra communities. [15].

The source data (and incidence map) showed that some LGAs had no cases of LF within the period under study; e.g. Akpabuyo, Biase, Boki, Calabar municipality, Calabar south, Obudu and Yakurr; and that in 2009 and 2013, there were no cases of LF in the state. This study has revealed the obvious misleading record after reviewing previous studies that reported incidences and prevalence in such areas: A study described cases of LF in Yakurr in 2009, with 6.1\% case positive for microfilariae and visually evident morbidity. [23]. Similarly, prevalence of Bancroftian filariasis (17.20\% case positive) had been described in a 2009 study in Calabar Municipality; while available records show zero case in the year and LGA in question. [17]. It is therefore instructive that the lack of data does not automatically foreclose the reality of LF prevalence in a particular area. This thus brings to light the challenges of poor reporting arising from poor health-seeking behavior; and poor acquisition/management of epidemiological data, which are required for disease control.

The overlays of vegetation and natural drainage maps on incidence map did not produce a visually remarkable pattern to suggest that these parameters influence transmission greatly. Although the highest incidence over the period was recorded within the guinea savanna vegetation zone, it concentrated in one LGA (Ogoja), while other LGAs had far lower cases (Fig. 2). Also, Figure 3 shows that the state is extensively drained, with many rivers, but the highland area (Obanliku LGA), though not with many rivers had cases higher than others (0.101-0.680 / 10000), as much as Akamkpa, which is a highly drained and forested LGA. Hence there is no specific pattern of transmission based on the availability of rivers. However, this may not be conclusive since the map does not show smaller water bodies like streams and rivulets. A previous study reported high prevalence and transmission rate of malaria in the highlands, suggesting that vector activity for LF may also be high there. [21]. Also, 82.12\% of the cases were recorded in the dry season usually marked by extremely low or no rainfall; the highest record was in November $(61.75 \%)$. However, knowledge of vector biology suffices it to argue that these environmental indices influence vector breeding and abundance, which would translate to effective transmission in an already endemic area. [24]. Again, it is presumable that a great many cases of the disease have not been reported. This raises great concern over the fate of intervention programmes and current efforts to eliminate the disease; of which Case Identification is the prime lead to cost effective use of resources, especially in mass drug administration (MDA). 


\section{Conclusions and Recommendations}

This study has produced thematic map that provides visual display of lymphatic filariasis in the state, which is useful in spatial analysis for accurate and cost effective intervention programmes. It has revealed the gaps in disease information management, especially in the area of case record; and identified the need for community health education to address issues of knowledge, attitude and practice, especially health-seeking behavior. While the need for intensive case identification and prevalence studies in noted, the study recommends strengthening of disease surveillance programmes in the state in order to procure and maintain reliable data for disease management; and intervention using mass drug administration (MDA) and integrated vector control.

\section{Acknowledgement}

We thank the management and staff of the Cross River State Ministry of health and WHO residence office in Calabar for assistance during data gathering for this study; and Dr. J. C. Udoh, University of Uyo for assistance in mapping.

\section{References}

[1] Roberts L. S. and Janovy, J. ( 2005). Foundations of Parasitology. McGraw-Hill, New York; 702pp.

[2] Wayangankar, S. (2015). Filariasis. Medscape. www.emedicine.medscape.com. Accessed 01/12/2016.

[3] Antinori, S., Schifanella, L., Million, M., Galimberti, L., Ferraris, L. et al (2012). Imported Loa loa filariasis: three cases and a review of cases reported in non-endemic countries in the past 25 years. International Journal of Infectious Diseases, 16(9):e649-e662, doi: 10.1016/j.ijid.2012.05.1023.

[4] PIH (2015). Loa loa - Subcutaneous Filariasis. Parasites in Humans. www.parasitesinhumans.org. Accessed 01/12/2016.

[5] WHO (2010). Progress report 2000-2009 and strategic plan 2010-2020 of the global programme to eliminate lymphatic filariasis: halfway towards eliminating lymphatic filariasis. World Health Organization. WHO/HTM/NTD/PCT/2010.6. Geneva.

[6] WHO (2016a). Global Health Observatory (GHO) data; Lymphatic filariasis. World Health Organization. www.who.int. Accessed 01/12/2016.

[7] WHO (2016b). Global programme to eliminate Lymphatic filariasis: Progress report, 2015. World Health Organization. www.who.int. Accessed 01/12/2016.

[8] Okorie, P. N., Ademowo, G. O., Saka, Y., Davies, C. O., Bockarie, M. J., Molyneux, D. H. and Kelly-Hope, L. A. ( 2013). Lymphatic filariasis in Nigeria; Micro-stratification Overlap Mapping (MOM) as a Prerequisite for Cost-effective Resource Utilization in Control and Surveillance.plos Neglected Tropical Diseases, 7(9): e2416.

[9] Braide, E. I., Ikpeme, B., Edet, E., Atting, I. and Kale, O. O. (2003). Preliminary observations on the occurrence of Lymphatic filariasis in Cross River State, Nigeria. Nig. J. Parasitol. 24: 9-16.

[10] Uttah, E.C., Simonsen, P. E., Pedersen, E. M, Udonsi, J. K. (2004). Bancroftian filariasis in the lower Imo River Basin, Nigeria. Afr. J. Appl. Zool. Environ. Biol. 6: 65-75.

[11] Ajero, c. m. u., Nwoke, B. E. B., Okolie, N. J. C., Nwanjo, H. U, Oze, G. et al., (2007).Bancroftian filariasis in the Niger Delta area of eastern Nigeris. Res. J. Med. Sci. 1:113117.

[12] Targema, C. N., Onwuliri, C. O., Mafuya, H. B., Mwansat, G. S., Aida, A. et al (2008). Mapping of Lymphatic filariasis in Benue State, Nigeria. Nig. J. Parasitology, 29:55-60. 
[13] Agi, P. I. and Ebenezer, A. (2009). Observations on Filaria Infection in Amassoma Community in the Niger Delta. Niger. I. Appl. Sci. Environ. Man. 1:15-19.

[14] Ojurongbe, o.,Akinbo, J. A., Ogiogwa, I. J., Bolaji, O. S and Adeyeba, O. A. Lymphatic filariasis in a rural community in Nigeria: A challenge ahead. Afr. J. Med. Sci. 39: 179-83.

[15] Okon, O. E., Ibor, C. I and Opara, K. N. (2010). Bancroftian filariasis among the Mbembe people of Cross River State, Nigeria. J. Vector Borne Diseases, 47(2):91-6.

[16] Uttah, E. C. (2011). Prevalence of endemic Bancroftian filariasis in the high altitude region of south-eastern Nigeria. Journal of Vector Borne Diseases, 48:78-84.

[17] Ekanem, I. A., Alaribe, A. A. A. and Ekanem, A. P. (2011). Prevalence of Bancroftian filariasis among Edim Otop sub-urban dwellers in Calabar Municipality of Cross River state, Nigeria. J. Appl Pharm Sci. 1:63-67.

[18] Manguin, S., Bangs, M.J., Pothikasikorn, J., Chareonviriyaphap, T (2009). Review on global cotransmission of human Plasmodium species and Wuchereria bancrofti by Anopheles mosquitoes. Infect. Genet. Evol. 10:157-177.

[19] WHO (2011). Position Statement on mapping morbidity and preventing disability in GPELF. World Health Organization,WHO/HTM/NTD/PCT/2011.8.Geneva.

[20] Hotez, P. J., Asojo, O. A. and Adesina, A. M. (2012). Nigeria: "ground Zero" for the High Prevalence Neglected Tropical Diseases. PLos Negl. Trop. Dis. 6:e1600.doi:10.1371/journal.pntd.0001600.

[21] Ukpong,I. G., Etim, S. E., Ogban, E. I and Abua L. L. (2015). Prevalence of Malaria in the Highlands of Obudu Cattle Ranch, Nigeria. International Journal of Tropical Disease and health, 7(3): 87-93.

[22] Ekpenyong, R and Ukpong I.G. (2003). Mapping the distribution of malaria incidence in Akwa Ibom State using G.I.S. Cartography, GIS and Sustainable Environmental Management. Nigeria Catography Association, University of Lagos, Lagos 79-93.

[23] Iboh, C. I., Okon, O. E., Opara, K. N., Asor, J. E. and Etim, S. E.(2012). Lymphatic filariasis among the Yakuur people of Cross River State, Nigeria. Parasite \& Vectors. 5:203. Doi:10.1186/1756-3305-5-203.

[24] Githeko, A., K., Lindsay, S. W., Confaloneri, U. E. and Patz, J. A. (2000). Climate Change and Vector-borne Diseases: A regional Analysis. Bull. World Health Organization.

*Corresponding author.

E-mail address: abraham.alemu@gmail.com 